\title{
A Structured Methodology for Business Network Design
}

\author{
Giacomo Copani ${ }^{1}$, Roberto Bosani ${ }^{1}$, Lorenzo Molinari Tosatti ${ }^{2}$, Américo Azevedo ${ }^{3}$ \\ ${ }^{1}$ IICS Srl - Industrial Innovation Consulting Services, Via S. Anna 12/a, 20014 Nerviano (Mi), Italy, \\ \{copani, bosani\}@iics.it \\ ${ }^{2}$ ITIA-CNR-Istituto di Tecnologie Industriali e Automazione, Viale Lombardia 20/a 20131 Milano (Mi), \\ Italy,l.molinari@itia.cnr.it \\ ${ }^{3}$ Inesc Porto - Institute for Systems and Computer Engineering of Porto and Faculty of Engineering of \\ University of Porto, Rua Dr. Roberto Frias, S/N 4200-465 Porto, Portugal, ala@fe.up.pt
}

\begin{abstract}
In the new manufacturing environment, a single enterprise does not often own all resources and skills to offer competitive solutions. Therefore, such enterprises become part of enterprise networks of independent core competencies in order to produce marketable products. Thus, Business Networking is an innovative business paradigm that can help companies to remain competitive in the market. Nevertheless, its practical implementation is very complicated because of the several dimensions that it involves, and, especially in network start up phase, because it is often left to the case and not managed with adequate methodologies and tools. The present paper proposes a structured methodology for long term business network design that is based on a network descriptive model and that should be applied by a "network architect". The proposed methodology has been developed and applied in the frame of KoBaS project funded through European Commission Program.
\end{abstract}

\section{Keywords}

Business Networking, Network design, Network set-up, Enterprise Networking, Network management.

\section{Business Networks as Competition Paradigm in Actual Environment}

In the last decades several big changes in technology, society, economy and politics, have seriously modified the environment in which enterprises operate. Market globalisation and deregulation, together with big privatisations of public companies in many states, allowed new players coming from emerging economies to compete in traditionally domestic markets on one side, and opened interesting internationalisation opportunities that only big companies could exploit before, on the other.

Customers are nowadays much more aware and demanding in their purchasing behaviour, asking for high quality products and services, willing to pay low prices and considering also environment impacts [Giacomazzi, 2002]. Business context became therefore more uncertain, dynamic and complex. Efficiency, which had been the most important critical success factor of previous years, characterised by a stable demand, low complexity products and lower competition, can no longer guarantee survival on the market [Chetty, Wilson, 2003] [Comari, 1993] [Robbins, Bergman, Stagg, Coulter, 2001]. Enterprises then started to respond to these changes developing new innovative products, offering advanced services, adopting new production strategies, such as Just In Time or Flexible Manufacturing, widely using Information Technology resources and implementing new management and organisational practices [Sturgeon, 2002].

Current business trends determined a move from vertically integrated companies towards flexible network organisations, where the ability to quickly and efficiently set-up, maintain, develop and dissolve partnerships with business partners is a critical success factor [Osterle et al., 2000]. Business networks emerge as a powerful mechanism to achieve competitiveness, world- 
excellence and agility in today's market conditions, comprising various entities with different competencies, but symbiotic interests [Azevedo 1999], [Azevedo et al., 2005].

The aim of this paper is to propose a set-up methodology in order to maximise the probability of long term Networks success. This paper underlines the need to consider several critical aspects that have to be fulfilled, emphasizing the importance of the main environment variables.

The remainder of paper is organized as follows. After this introduction, next section presents main problems and difficulties for business networks success usually considered by several researchers. The third section proposes a structured approach as a methodology for network setup. The fourth section addresses the application of proposed methodology in a large on-going European Project [KoBaS, 2006]. The fifth and last section contains the conclusions of the paper.

\section{Problems and Difficulties for Business Networks Success}

Despite the fact that Business Networking and strategic cooperation networks are emerging as a valuable organisational instrument that can create considerable competitive advantage for small firms, unfortunately, its practical implementation is very complicated. Some studies estimate that up to $60 \%$ of the alliances fail to meet their initial objectives [Ellis, 1996], in a clear indication that there is still a lot of work to be done regarding the creation and management of these networks [Caldeira, 2004]. This is due to the complexity of several dimensions that the concept of Business Networking implies and to some confusions and lacks arising from the fact that the argument only started to be treated as a managerial and organisational topic a few years ago.

The first difficulty arises from the need to define and agree among Network participants about the meaning of a Business Network. Many definitions can be found in literature treating the network using the social approach or the business approach [Wu, Sun, 2002][ Osterle, Fleisch, 2000][Torelli, 1986][Comari, 1993]. However, there is too little systematic knowledge about the structure and the behaviour, of enterprise networks of integrated, multi-dependent nodes [Thoben, Jagdev, 2001]. In fact, one of the main findings and recommendation of the THINKcreative project points to the urgent need to invest time and effort into creating a sound theoretical foundation, where appropriate definitions shall be established for the general area of collaborative organisations [Camarinha-Matos, et al., 2004].

Secondly, the high failure rate of Networking initiatives can be attributed to the lack of a structured and professional management approach in all life cycle network phases: set-up, operation, evolution and dissolution [Wu, Sun, 2002]. Even if rational facts like increase of market share, new business or cost reductions are key factors in evaluating the interest of a collaboration, "soft" factors like the exchange of experience and knowledge, human factor and sharing of common activities should not be underestimated [Pouly et al., 2005]. Authors' experience shows that very often, networking is considered a spontaneous phenomenon that is self-developed under certain environmental conditions. Even after the formal recognition of its existence, on-purpose defined management procedures are not often applied and organisational infrastructures for their management are not created.

Following paragraphs treat the current state of the art about Network business meaning and conditions to be fulfilled for its success.

\subsection{Network Typologies}

There can be a high number of possibilities by which enterprises can collaborate creating business networks. Business Networks can be divided on the basis of their specific scopes in:

- Research network, in which partners cooperate in research activities whose results are inputs for products development [Hanna, Walsh, 2002].

- Product development networks, which can be implemented as horizontal networks (network partners operate at the same level of the supply chain), vertical networks 
comprehending a leading company with its suppliers (network partners cover different stages of the supply chain) or can be composed of several specialised companies, each one uncharged individually for a specific development task focused on its own competencies and resources [De Toni, Nassimbeni, 2001].

- Production networks, which can be either horizontal or vertical, depending on the particular industrial field in which they operate and on the required specialisation level for products and components production [Sturgeon, 2002].

- Supply chain networks, which are vertical networks with a high cooperation and coordination level of activities between partners, which permits to reach high global supply chain efficiency [Rehm, Chourmouziadou, Copani, Rossi, 2003].

- Support networks, which are networks created for the common management of enterprises support processes like logistics, human resources, information technology and foreign commercial activities management [Chetty, Wilson, 2003]

\subsection{Critical Aspects for Networking Success}

From a strategic, business and organisational point of view, several critical success factors have to be fulfilled for network success, namely, the participants and their roles need a business model to describe their relationships and interaction as well as how value is created and shared.

The first necessary condition is a real and strong commitment of all members. If network is considered by its members as an alternative and secondary way to the traditional business, it will be difficult for it to succeed. The reason comes from the complexity of the network itself that, in order to work properly, forces partners to serious and continues efforts that are in general not compatibles with short term logic or a partial shared vision, typical of an opportunistic behaviour. In order to have a serious partner's commitment, it is necessary that network members jointly define network vision and mission, and that they identify themselves with them without any reservation [Das, Ten, 1998].

The second fundamental condition for network profitable survival is trust, identified by many authors as one of the main causes of networks failure [De Ottati, 1994][Hanna, Walsh, 2002]. Trust is so important because networks members have to share and make public confident information related to strategy, business processes, competencies that are often the source of competitive advantages. If members are not convinced about the ethic and business principles of the other network partners, they will not share resources and knowledge [Torelli, 1986].

From an operative point of view, the main difficulty that has to be faced for networks efficiency is the design of network business processes that cover the needs of specific business purposes on one side, and that reasonably fit with single business processes of network members. The last crucial aspect to point out as a possible barrier for network consistence, is the definition of the most appropriate legal structure that formally identifies responsibilities and liabilities of network members regarding stakeholders. This legal structure must fit with the strategic and operative network needs and, thus, can not be chosen separately from all fundamental elements above mentioned [Alive, 2001].

\section{Proposal of a Methodology for Network Set-up}

This section presents a structured management approach, as a methodology, to fill the lack of managerial approach for network design and set-up phase, the most critical for network success.

\subsection{A descriptive model for Business Networks}

A methodology has to be applied on clear concepts and input data. In order to overcome the confusion around Business Networking concept and definitions, we propose a descriptive model of Business Networks, which clarifies concepts and vocabulary. 
We aim at a business network, generally, as a group of autonomous enterprises that interact for common goals, sharing a common vision and mission. Under this general definition, a business network can assume several implementation forms, characterised by different business processes and interactions between network members: a district, a joint venture, a business consortium, a partnership, a licensing agreement, a virtual enterprise, a dynamic business network, a strategic alliance, an outsourcing agreement, a resource sharing agreement, lobbying alliances, Japanese network forms of "Keiretsu" and "Zaibatsu", etc.

Each particular form of business network is determined by the value assumed by thirteen "network configuration variables", which represent the fundamental dimensions upon which a network is built. The value of these variables is influenced in turn by six "environmental variables”, representing the external context in which network operate (Figure 1).

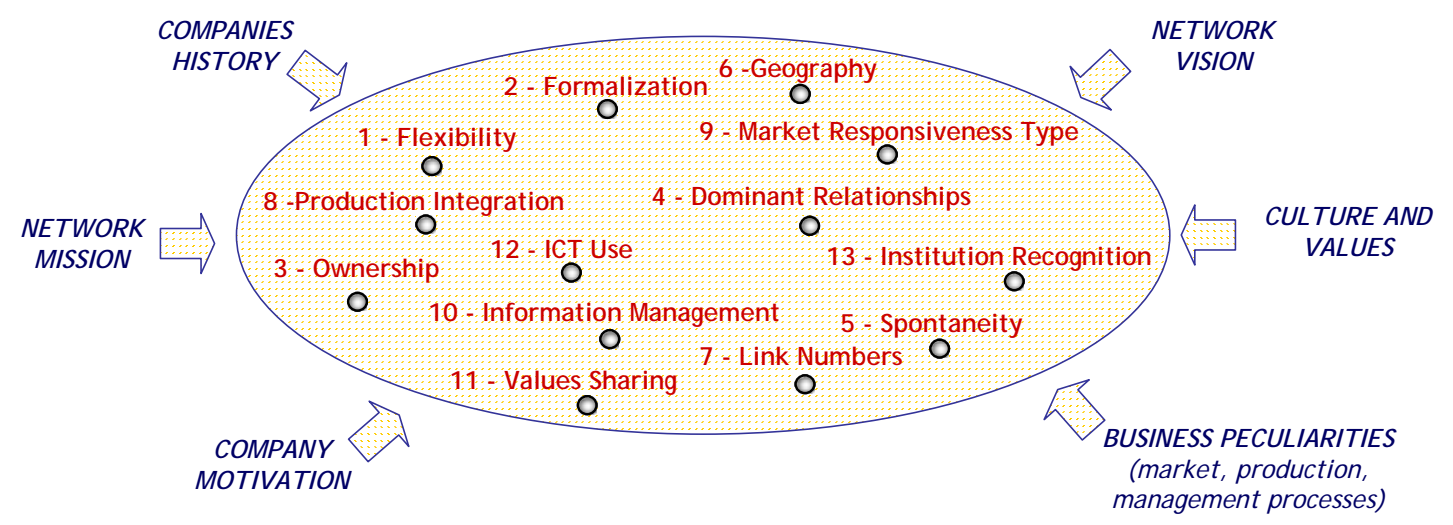

Figure 1: Network configuration variables and environment variables

\subsection{Structured three steps methodology for Network set-up}

Referring to the network descriptive model presented in the previous paragraph, the methodology for long term network design and set-up consists of three steps: evaluation of six environmental variables, strategic network design and operative network design and set-up. The methodology requires that an actor with adequate competencies takes care of the design and set-up phase, the "network architect". The network architect can be a network member, but in this case his own interests in the network could interfere with the efficacy of the design process and could create some relational trouble while interacting with other partners. The best solution should be to have an external network architect with specific competencies in networking, business process design and in the business field in which the network will operate.

\subsubsection{Evaluation of six environment variables}

The first step of the methodology is the understanding of environment variables that determine the most appropriate type of network that has to be built. To do this, it is fundamental to involve all future network members, since, as previously explained, network success deeply depends on the fact that all members recognise their own values in the network and find advantages in it. The procedure to gather the necessary information is reported below:

- A first general meeting, in which the network project and its implementation procedure are explained, has to be organised in order to share opinions and suggestions from all future members. This meeting is important to gather possible resistances and difficulties during set-up process, and to anticipate their solution too.

- A campaign of single interviews (or questionnaires) has to be conducted in order to get the particular point of view and situation of each single partner. Interviews should be conducted following a structured common guideline that alows to collect both qualitative and quantitative data and information, with the possibility of confronting them using predefined criteria. 
- Using collected information, the architect has to elaborate a draft hypothesis of network vision and mission. This hypothesis has to be discussed by partners in a second collegial meeting, eventually modified and, at the end, has to reasonably satisfy all partners, since it represents the intent declaration of the network: without this basic condition, there will be few possibilities of success.

\subsubsection{Strategic network design}

Based on detected environment variables and on his specific competencies and knowledge, the architect has to define a coherent general model of network configuration, which should be expressed in terms of macro business processes, macro organisational structure and strategic management principles.

The general configuration model has to be presented to all future network members in a new meeting. The model will have to be approved by network members before going to the third phase of the methodology, since it expresses the fundamental concepts of network future operation. Except for the rare cases in which all partners immediately agree about the proposal, it will be necessary for the architect to consider the reactions to his proposal and to elaborate and propose new improved versions of the general configuration model, until a reasonable final satisfaction is reached about it.

\subsubsection{Operative network design and set-up}

The approved general configuration model is the input that drives the architect in the detailed design of all the operative network elements: network legal structure, network knowledge base, network business processes and network organisation. The detailed design of these operative elements, corresponds to the assignation of a value to the thirteen network configuration variables (Figure 1), determining thus the particular network implementation form.

A network legal structure has to be properly chosen in order to enable the formal identification of the network from external stakeholders, to legally allow the network to run its business and to clearly define liabilities and responsibilities of network partners. In the case of international networks, particular care has to be taken about this task, because legislations of different countries are not often based upon the same legal principles [Alive, 2001]. The first main choice to be faced is the decision about legal or not legal personality. The first one guarantees maximum formalisation, partners safety and external clear identification, but presents high set-up and management costs. The second one ensures a major operative flexibility and changes possibilities over time, but with a bigger individual partner risk. Afterwards, the specific legal form to be used has to be defined, like, for example, a joint venture limited liability company, a consortium agreement, a strategic alliance, a private contract, etc.

The network knowledge base is a structured repository of all the knowledge about the network. Its main scopes are to enable a better mutual partners knowledge and to support network activities, like for example, the creation of a specific proposal of project team for the fulfilment of a particular customer request, or the evaluation of the opportunity to let a new member access the network with respect to competence duplication, etc. The knowledge basis has to be structured for each partner in four main knowledge areas: general information about network members, offered products and services, resources, market and strategy.

Detailed business processes must describe all activities that will have to be performed for network operation and their right execution ways, together with support information technology instruments (administration, marketing, logistics, production ...). Business processes should be mapped with a specific tool and retained in the network knowledge base for public consultation from all members.

Network organisation structure has to clearly define what all network organisational entities are (single network members, but also committees, possible external actors like a network architect or coordinator, ...), what their roles and responsibilities are (to which business processes they 
have to contribute and what deliverables they have to produce) and what coordination mechanisms they have to use in order to perform their tasks.

Once again, the network architect should autonomously prepare a proposal for the detailed network operative model, submit it to all network members in a collegial meeting and modify it considering all critics and suggestions until a final agreement is reached. Since details to be explained during this process are generally very difficult transmit with traditional exposition techniques, it is convenient to present them simulating real business scenarios.

The three steps of the methodology are summarised in the following picture.

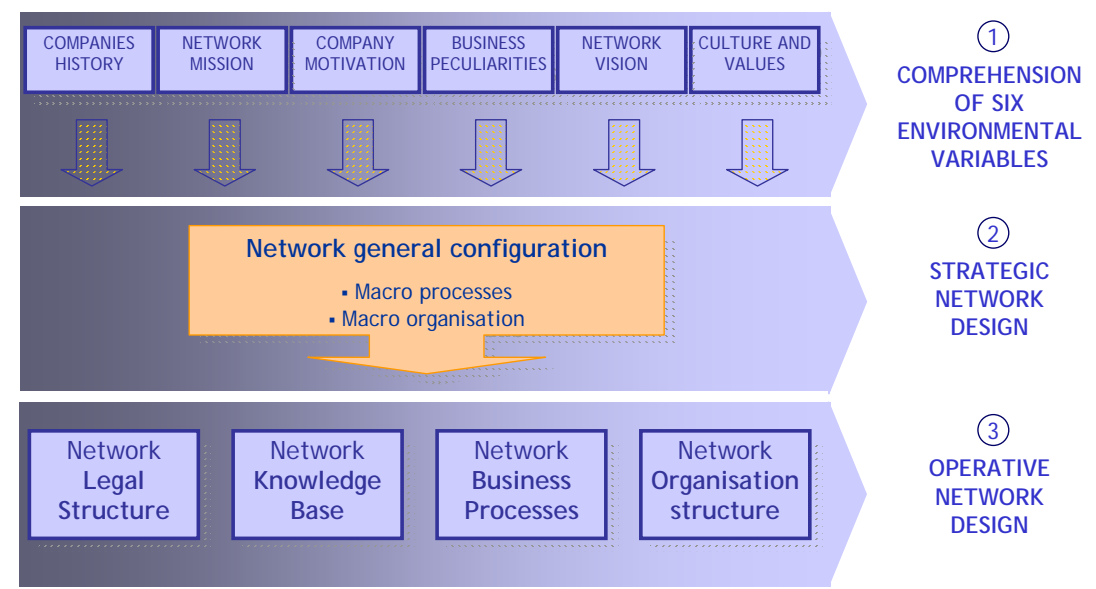

Figure 2: Structured three steps methodology

\subsection{Advantages and problems of the methodology}

The main advantages of the presented methodology for network design are:

- Design decisions are taken following a hierarchical logic, which guarantees that detailed aspects are not considered before the basic ones and before having deeply understood the context; this avoids effort dispersion in fragmentary activities, very frequent in network design because of the complexity and variety of the Business Networking concept itself.

- Decisions are taken involving all future network members in the design process and considering their opinions; this maximises the probability that partners will operate in a network that will reflect their own values, intentions, which will be compatible with their own procedures and infrastructures, and will promote their future commitment.

- The role of an external network architect owning adequate competencies of networking business process and organisation, guarantees that the design phase is conducted with the management principles needed by a start up on one side, and contributes to reduce possible conflicts that can arise from single partners that wish to acquire a dominant role in the future network on the other.

On the other hand, the problems to be faced for the application of the methodology are:

- Time of all design process could be considerable, especially if future partners are not homogeneous in terms of company size, business fields, cultural level and intentions.

- Costs for travels, interviews and meeting organisations could be consistent, especially in the case of geographically dispersed networks.

- The "democracy" of the network design process can be the cause of the loss of some partner that prefers to abandon the initiative because decisions taken step by step in order to mediate mutual needs do not satisfy them. At the end, these defections have to be considered positive and physiological events, since they make it possible to create networks composed of committed and well intentioned partners from the preliminary phases. 


\section{Application of the Methodology}

The structured methodology for long term Network design has been developed and applied in the KoBaS Project [KoBaS, 2006]. The project consortium involves twenty one partners from ten countries, in which six partners are European R\&D Institutions, seven high-tech companies, four machine tool builders and three manufacturing end users. The objective of KoBaS project is to create a network of high-tech small and medium enterprises, offering knowledge based services developed within the project to manufacturing companies operating in traditional sectors. Knowledge based services will be a customised integrated solution of KoBaS "components", which will be modules developed for specific purposes.

The first step of the methodology, consisting in the evaluation of environmental variables, has been carried out with a questionnaire campaign performed after a general meeting. The questions addressees were grouped in five areas, exploring the types of interactions between companies and their market, the peculiarities of the market itself, the general characteristics of products and services, managerial skills, operative tools and competencies, and the expectations from network constitution. Network vision and mission have been proposed by a project partner acting as network architect, deriving it directly from the project aims and philosophy, and have been approved during a collegial meeting.

The output of second step of the methodology has been a general network configuration model in which two networking levels are foreseen: a strategic level (being stable over time, having a strategic management purpose and dedicated to network infrastructure management), and a task level (being temporary, having operative purposes and dedicated to single jobs management). Typical macro processes at strategic level will be administration and legal issues, rules definition and maintenance, strategic marketing and planning, strategic new products and service development, while at task level will be products and services supply, proposal management, operative marketing and planning, operative new products and service development. Macro organisational structure has been defined in terms of organisational entities (network Consortium, network Strategic Committee, network Project Team, network Proposal Team, network Coordinator, network Architect and network Competence Centre) and of their contribution to macro business processes.

The third methodology step is still running. Some decision has already been taken about network legal form (a consortium agreement between all partners has been chosen) and a first draft version of the network knowledge base is already available.

The experience showed that the action of a professional Network Architect is fundamental to mediate different positions and to find managerial solutions to divergences and problems, especially if set-up times are long like in $\mathrm{KoBaS}$ project and a project management approach is needed.

\section{Conclusions}

With the aim to fill the lack of managerial approach in networks set-up, a structured three steps methodology for long term Network design has been proposed. The methodology is based on a descriptive model of business network and foresees that an actor with adequate competencies takes care of the design and set-up phase, the "network architect". The three steps are the evaluation of environmental variables, strategic network design and operative network design. The methodology has been applied in the frame of KoBaS European research project and, although preliminary experience has clearly proved the potential of this approach, the growing importance of this subject justifies further work. Authors intend therefore to explore this line of research, namely in understanding the mechanisms for support the design and set-up of networked enterprises and in developing collaborative and negotiation methodologies for business networking environment. 


\section{Acknowledgement}

This work has been partly funded by the European Commission through Project KoBaS: Knowledge Based Customized Services for Traditional Manufacturing Sectors Provided by a Network of High Tech SMEs (No. 505339-2 FP6-2002-NMP-2). The authors wish to acknowledge the Commission for their support and KoBaS project partners for their contribution during the development of various ideas and concepts presented in this paper.

\section{References}

Alive: Advanced Legal Issues in Virtual Enterprise (European Project IST-2000-25459) WWW page. http://www.vive-ig.net/projects/alive/docs.html, accessed 10.1.2006.

Azevedo, Americo: Decision Support for the Negotiation of Orders in Enterprise Networks, PhD Thesis - Faculty of Engineering of the University of Porto, 1999

Azevedo, A.; Toscano, C.; Sousa, J.P.: Cooperative Planning in Dynamic Supply Chains, International Journal of Computer Integrated Manufacturing, Vol. 18, No 5, 2005, p. 350-356

Caldeira, J.C.: Joint Ventures for Innovation \& Competitiveness, in E-Manufacturing: Business Paradigms and Supporting Technologies, Edited by João José Pinto Ferreira, Kluwer Academic Publishers, 2004

Camarinha-Matos, L.M.; Afsarmanesh, H.: Collaborative Networked Organizations: A Research Agenda for Emerging Business Models, Kluwer, 2004

Chetty S.K.; Wilson H.I.M.: Collaborating with competitors to acquire resources, International Business Review, v12 i1, 61(21), 2003

Comari A. M.: Il modello flessibile della virtual corporation, L’impresa, v8, 14(4), 1993

Das T., Teng B., Between trust and control: developing confidence in partner cooperation in alliances, Academy of Management Review, 1998, v23 i3, 491(22)

De Toni A.; Nassimbeni G.: A method for the evaluation of suppliers' co-design effort, International Journal of Production Economics, v72 i2, 169(12), 2001

Dei Ottati G.: Trust, interlinking transactions and credit in the industrial district, Cambridge Journal of Economics, v18, 529(18), 1994

Ellis, Caroline: Making Strategic Alliances Suceed, Harvard Business Review, 1996

Giacomazzi F.: Marketing Industriale, McGraw-Hill, 2002

Hanna V., Walsh K.: Small firm networks: a successful approach to innovation?, R\&D Management, v32, 2002

KoBaS: Knowledge Based Customized Services for Traditional Manufacturing Sectors Provided by a Network of High Tech SMEs . WWW page. http://www.kobasproject.com, accessed 10.1.2006.

Osterle, H.,; Fleisch, E.; Alt, R.: Business Networking, $2^{\text {nd }}$ Edition, Springer, 2000

Pouly, M.; Monnier, F.; Bertschi, D.: Success and Failure Factors of Collaborative networks of SME, in Collaborative Networks and Their Breeding Environments, Springer, 2005

Rehm S., Chourmouziadou Z., Copani G., Rossi A.: Textile Extended Enterprise Network Management On ECollaboration Platforms, Anipla Proceedings, 2004

Robbins S.; Bergman R., Stagg I., Coulter M.: Management, Prentice Hall, 2001

Sturgeon T.J.: Modular production networks: a new American model of industrial organization, Industrial and Corporate Change, v11 i3, 451(46), 2002

Jagdev, H.S.; Thoben, K.-D.: Typological issues in enterprise networks, Production Planning \& Control, Vol 12,No.5, p. 421-436, 2001

Torelli H.B.: Networks: Between Markets and Hierarchies, Strategic Management Journal, v74 i1, 37(15), 1986

Wu N.; Sun J.: Grouping the activities in virtual enterprise paradigm, Production Planning and Control, v13i4, 407(9), 2002 